\title{
Economic Freedom, Migration and Income Change among U.S. Metropolitan Areas
}

\author{
J. Matthew Shumway \\ Brigham Young University, USA \\ Email: jms7@byu.edu
}

How to cite this paper: Shumway, J. M. (2018). Economic Freedom, Migration and Income Change among U.S. Metropolitan Areas. Current Urban Studies, 6, 1-20. https://doi.org/10.4236/cus.2018.61001

Received: July 18, 2017

Accepted: February 10, 2018

Published: February 13, 2018

Copyright $\odot 2018$ by author and Scientific Research Publishing Inc. This work is licensed under the Creative Commons Attribution International License (CC BY 4.0).

http://creativecommons.org/licenses/by/4.0/

(c) (i) Open Access

\begin{abstract}
Even though metropolitan area governments have no control over state level monetary, labor, or fiscal policies, they are able to enact policies designed to enhance local living conditions-however determined. Such policies include local taxes, labor and wage policies, and regulations that can differ substantially from other metropolitan areas even within the same state. Collectively such policies create differing levels of economic freedom, as measured by standardized indices. We examine differences in levels of economic freedom across United States metropolitan areas and explore how these differences affect migration patterns and local aggregate and per capita income changes. We find that those metropolitan areas with higher levels of economic freedom tend to experience net in-migration and positive changes in aggregate and per capita income, although the balance between in-state and out-of-state migration confounds these patterns.
\end{abstract}

\section{Keywords}

Economic Freedom, Migration, Income Change, U.S. Metropolitan Regions

\section{Introduction}

On January 1, 2016, the billionaire head of Appalossa Management, David Tepper, moved his headquarters and personal residence from New Jersey to Florida. What is interesting about this move is that it was immediately noticed by the New Jersey Office of Legislative Services, which reported that the state will be feeling the impact of this one move on their income-tax forecast (Dopp, 2016). The state of New Jersey receives almost 40 percent of their revenue from personal income taxes and more than a third of that 40 percent comes from the top one percent of taxpayers. Mr. Tepper, with a personal fortune of an estimated ten 
billion dollars, is at the top of that one percent (Dopp, 2016). According to the Tax Foundation in Washington D.C., New Jersey has the country's third highest tax burden while Florida residents are free of any personal-income or estate taxes. As thousands of others before him, and undoubtedly as many more to come, David Tepper voted in the most meaningful way possible on the state of New Jersey's tax policies-he left.

This anecdote suggests that the quality of institutions (e.g. local government polies such as individual and corporate income tax rates) matters in how it affects individuals, businesses, and the ability of local governments to enact and carry-out particular policy decisions. At a global level, there is compelling evidence that good institutions-particularly private property, rule-of-law, freedom of entry and exit into occupations, and freedom to trade-create conditions that foster economic growth and improvements in the quality-of-life (Galor, 2011). Current research provides evidence that countries with lower capital and wage tax rates, fewer barriers of entry into markets, and rule of law, along with political stability and good governance, tend to have higher rates of economic growth, employment and entrepreneurship (Goldsmith, 1995; Ali, 1997; Farr et al., 1998; Ayal \& Karras, 1998; Heckelman 2000; Heckelman \& Stroup 2000; Ali \& Crain, 2002; Carlsson \& Lundström, 2002; Dawson 2003; Gwartney \& Lawson, 2006; Xu \& Li, 2008; Faria \& Montesinos, 2009; Bergh \& Karlsson, 2010; Cebula \& Clark, 2012; King et al., 2012; Cebula, 2014; Kuckertz et al., 2016). With few exceptions, this research suggests that economic freedom is a key to prosperity.

Economic freedom is organized as a competitive market in which resources are allocated through the private decisions of individuals rather than government (decentralized versus centralized decision making). Important components of economic freedom are similar to ideas of what constitutes good institutionslimits on coercive property and income taxes, the extent of government control over the private sector (e.g. regulations that restrict entry into markets), the liberty to work at the occupation and remuneration of one's choosing (e.g. unnecessary licensing requirements), and the ability to buy or sell goods at prices determined independent of the government (Friedman, 1962). It also includes positive aspects of government, including the protection of life, private property, and the adjudication of disputes. Another important element of economic development that is sometimes overlooked, however, is freedom of movement. Acemoglu et al. (2005) suggest that population change, including and largely as a result of migration, is both a signal of and a causal factor in local institutional practices through Tiebout (1956) migration (i.e. "voting with their feet") and the resulting compositional mix of local populations.

Our goal in this paper is to explore how varying levels of government control affect the size and direction of migration and income among metropolitan areas within the United States-a federal state that contains multiple levels of governments. In particular, we investigate the impact of local government policy on revealed locational preferences using Tiebout's (1956) "vote with their feet" 
model. In our analysis, we seek to provide an increased understanding of how local levels of economic freedom affect population and income change through migration. The analysis contributes to the existing literature on the link between local government quality and sub-national or regional outcomes by providing evidence that internal, interregional migration affects and is affected by the quality of local government policies.

\section{Conceptual Framework}

Our analysis is based on the assumption that individuals' reveal their locational preferences by "voting with their feet" (Tiebout, 1956). Using previous research as a guide (Faggian et al., 2012; Ferguson et al., 2007; Partridge, 2010), we assume that persistent net migration rates show which locations are more-or-less preferred, which can then be associated with varying levels of regional attractiveness. That is, migration may be a suitable predictor of individuals' actual locational preferences. We also assume that individual behavior is utility maximizing relative to pecuniary as well as to non-pecuniary costs and benefits of different locations.

Conceptually, high levels of economic freedom create conditions within which innovation takes place, and innovation is a key driver of economic development (Romer, 1990). Innovation occurs endogenously as individuals seek to improve their human capital. As investments in human capital increase, so does specialization, which in turn raises the returns to those who specialize in new knowledge and technologies. Since new knowledge and technological skills are rare, the returns are higher (Rosen, 1983). This process also increases entrepreneurship because individuals seek to benefit from the application of their new knowledge in innovative ways, as long as the returns are not unfairly expropriated by the political process (Romer, 1986, 1990). If the novel market opportunities are removed or limited, then the returns to skills and the incentives to invest are diminished and economic growth slows (Lucas, 2002). Economic freedom also enhances the efficiency by which productive inputs are converted into output via increasing total factor productivity (vis-à-vis investments in human capital and technological change) and by enhancing capital accumulation.

On the other side, local governments use tax competition as a way to promote and attract productive activity. Tax competition is the freedom for a jurisdiction to set lower taxes or put in place a different tax system. In the last three decades, national governments have increasingly engaged in tax and regulatory competition by lowering trade barriers and decreasing capital controls. This has led some states (national and international) to lower top tax rates, leading to a "tax cut revolution" encompassing individual income, individual capital gains, dividends, wealth, corporate income, corporate capital gains, and cross-border investment (Edwards \& Mitchell, 2008). One important effect of tax competition is its beneficial impact on saving, since lower taxes encourage capital accumulation. This in turn leads to more investment, more jobs and more economic welfare. 
Beyond its effects on prosperity by limiting the tax burden, tax diversity enables the implementation of new practices and innovative institutional ideas at more local levels. The need for individual, temporary and customized solutions is increasing, while the need for coercive measures applying equally to all is decreasing. Tax diversity takes into account this evolution arising from societal and technological progress that allows new and increasingly smaller geographic units to create a competitive advantage in an increasingly globalized world.

\section{Federal States}

The effect of freedom on economic growth is not limited to sovereign states. Recent research illustrates that the same benefits can accrue within sovereign countries that are federally organized (Holcombe \& Lacombe, 2004; Ashby, 2007; Ashby \& Sobel, 2008; Cebula, 2014; Heller \& Stephenson, 2014; Compton et al., 2011). In political states with federal systems of governments, the movement of goods, information, and people are axiomatic (Weingast, 1995). For example, one of the reasons for migrating across internal political borders is to take advantage of local differences in political and economic regulations, taxes, and public goods. Conceptually, spatial diversity of public goods is preferred because the governmental provision of local goods and services can be tailored to particular local circumstances that will result in increased levels of economic welfare when compared to a uniform national provision of equivalent goods and services. Since costs and preferences vary across jurisdictional subunits, government provided goods and services are more efficiently provided locally, i.e. where the sum of resident marginal benefits equal marginal costs, thus maximizing overall welfare (Oates, 2003). In Tiebout's (1956) famous model, households "vote with their feet" by moving to jurisdictions that provide a set of local public goods and services that align with their preferences. Migration is a signal that citizens send to local governments indicating approval or disapproval of public policy. The closer political decisions are taken to those most affected by these decisions, the easier it is for residents to vote with their feet by moving to another jurisdiction, resulting with public policies matching the residents' actual needs and preferences. This suggests that local jurisdictions with some control over tax and regulatory policies will create varying types of tax and regulatory systems, which will in turn influence who migrates in, migrates out, and who stays, ceteris paribus. Thus, the decision to migrate or stay is the manifestation of a household's demand for a particular mix of public goods and local taxes (Tiebout, 1956; Tullock, 1971). Current research is finding that subnational units with greater degrees of economic freedom almost always experience higher rates of economic growth, all other things equal (Ashby \& Sobel, 2008).

Besides economic growth, varying levels of economic freedom also affect migration selectivity, i.e. who moves and where, and who doesn't move. States with higher relative levels of economic freedom attract retirees (Clark \& Hunter, 1992), labor force migrants (Ashby, 2007; Cebula, 2014), migrants with higher levels of 
education (Mulholland \& Hernandez-Julian, 2013) and income (Shumway \& Davis, 2016). However, using state-level data can hide what may be large variations within a state (Stansel, 2013). In addition, since migration is highly sensitive to distance, most moves are local. That is, there is more intrastate than interstate migration. Thus "voting with your feet" is going to be more likely to occur between cities within the same state or within cities that cross state boundaries that have different levels of economic freedom. Finally, because metropoli$\tan$ areas tend to emerge from the interactions of millions of economic agents, they more resemble the actual geography of economic activity and thus provide a better framework to examine differences in economic freedom and its effect on migration than do states and nations-with the caveat that metropolitan areas are unable to determine and must abide by monetary, fiscal and regulator rules of their states and nations. Nevertheless, the differing levels of economic freedom at the metropolitan level provide a nice case study within which to examine income migration.

This paper is a descriptive exercise for the purpose of examining changes in aggregate and per capita income at the metropolitan level relative to differing levels of economic freedom. Our expectation is that areas with greater levels of economic freedom will have higher levels of net in-migration, aggregate and per capita income.

\section{Data and Methods}

For this paper we use two main sources of data. First we use the Economic Freedom Index for U.S. Metropolitan Areas (EFIMA) created by Dean Stansel (Stansel, 2013). This index is a composite measure of ten variables measured in three areas: 1) size of government, 2) takings and discriminatory taxation, and 3) labor market freedom. It is patterned after the Economic Freedom of North America index created by the Fraser Institute. For area one, the index is based on the combined burden of state and local government as measured by size of government (government spending on consumption, transfers and subsidies, public pensions, and unemployment compensation all relative to local personal income). Area two of the index is mainly composed of tax revenues (direct, indirect, and sales taxes) as a percentage of personal income. The labor market freedom component of the index is made up of three components: minimum wage annual income as a percentage of metro area per capita income, state and local employment as a percentage of total employment, and union density. Similar to the North American Index, each variable is standardized and scaled to be between zero and ten. The variables are averaged in each of the three main areas, thus creating sub-indices for each area, and then the three sub-area components are averaged to create the overall economic freedom score for metropolitan areas in the U.S. The final Index uses a ten-point scale with higher numbers indicating more economic freedom. All variables are equally weighted. For a detailed description of the methodology and data sources see Stansel (2013). 
The EFIMA includes 384 metropolitan areas defined by the Census Bureau as of 2009. Of these 384 metropolitan areas, 355 are defined as metropolitan statistical areas (MSA) and 29 as metropolitan divisions (MD). MDs are component areas of large MSAs. There are 43 metro areas that cross state boundaries. For these, the EFIMA uses data from the state with the largest proportion of the city within its boundaries. Here we use the EFIMA as a tool to categorize 361 metropolitan areas (we only use the metro areas in the 48 contiguous states and there were a few metro areas with incomplete data so our sample was reduced from 384 to 361) relative to their levels of economic freedom. Metropolitan areas are classified into three categories using standardized z-scores. We use the overall economic freedom index as well as each of the smaller area indices (size of government, takings and discriminatory taxation, and labor market freedom) to categorize metropolitan areas, using standardized z-scores, into one of three categories: high, medium, and low levels of economic freedom. Once we have categorized all of the metro areas, we then examine migration and income change across the three categories.

For migration and income data we use the 2011 to 2014 county-to-county income-migration data set created from administrative IRS data (US Internal Revenue Service, 2015). The income-migration data matches individuals by their social security numbers from one tax year to the next. The IRS data has several advantages over other data sets for examining U.S. internal migration, including providing year-to-year estimates over a long period, it is administrative and not survey data, it includes a measure of income, and starting with the 2011 data the IRS made a number of changes that improved the quality of the data, although this discontinuity limits comparisons to pre-2011 data. To increase coverage, the data now includes all tax returns filed between January 1 to December 31 whereas previous data were based on tax returns only through the end of September. The income-migration data also matches returns based not only on the primary taxpayer identification number (95 percent of all matched returns), but also secondary (two percent) and dependent tax filers (three percent) as well. One of the best features of the new data reporting scheme is the inclusion of the age of the primary taxpayer, although this information is only provided in the state-to-state files and not the county-to-county files (the data users guide contains additional details, IRS 2013).

The IRS income-migration data also has some characteristics that limit its usefulness. One issue is population coverage. The IRS migration data coverage is not complete and those left out may bias the results. For example, individuals/households that do not file tax returns are not included in the data. This population is most likely to include the young, low-income, homeless, illegal residents, felons, students, and even some retirees. The overall effect is likely an undercount of actual migrants. These effects are likely to be compounded at smaller geographic scales. While there are limited means of mitigating the bias 
issue, the point is to be cautious in generalizing beyond what the data gives us.

A second issue to be aware of is that the data does not measure the movement of income, it simply matches addresses of those who file income tax forms with the IRS. Thus, it is measuring the movement of people that includes their reported incomes at the new location. Incomes earned in one county do not actually move to the new county. Households move and earn income in two different places, although unearned income, wealth, and human capital do change locations. What we are actually examining is the changing level of aggregate and per capita income at the county level (aggregated into corresponding metropolitan areas) before and after migration. This is not simply the average income of a metro area from one year to the next. Pre-migration income estimates include the relevant population of each metro areas' non-migrants as well as the income of their out-migrants. Post-migration income includes non-migrants plus in-migrants (Plane, 1999). Thus this data does not show the flow of income from one metropolitan area to another, but instead reveals how income (aggregate and per capita) changes as a result of migration. The difference (increase or decrease) in aggregate income associated with in- and out-migration is what Plane refers to as income-migration.

Methodologically, we measure change in aggregate income as differences in net migration and differences due to differential household incomes among inand out-migrants. For example, a metropolitan area's change in aggregate income due to migration consists of the interplay between net migration and the differential income of in- and out-migrants. We first disaggregate income migration into its component parts, which are: differences due to net migration, and differences due to differential household incomes among in- and out-migrants. A metropolitan area's change in aggregate income (due to migration) consists of these two components:

$$
Y_{N}=Y_{N} N M C+Y_{N} D I C
$$

where in- and out-migrant income can be further defined as:

$$
Y_{I}=y_{I} I \text { and } Y_{O}=y_{O} O
$$

Here $y_{I}$ and $y_{O}$ are per capita income levels of in- and out-migrants and $I$ and $O$ represent the gross number of in- and out-migrants. Further, the difference between in-migrant and out-migrant per capita income, $d$ is:

$$
d=y_{I}-y_{O}
$$

and $y^{*}$ is defined to be the average of in-migrant and out-migrant per capita income:

$$
y^{*}=\frac{y_{I}+y_{O}}{2}
$$

With these equations, we then calculate income change due to net migration as: 


$$
Y_{N} N M C=y^{*}(I-O)
$$

This equation conveys what the gain or loss in aggregate income would hypothetically be if in-migrants to and out-migrants from specific metropolitan areas have identical levels of per capita income. The difference between this amount and the actual change in aggregate income attributable to migration is then ascribable to the difference between in-migrant and out-migrant per capita income, which is measured by:

$$
Y_{N} D I C=\frac{1}{2} d T
$$

where $T$ is total migration. This component reflects the difference between in-migrant and out-migrant per capita income weighted by the total volume of migration (see Plane, 1999 for a more detailed discussion).

In summary, using the formulas developed by Plane (1999), we disaggregate changes in aggregate income into two components: the net migration component and the differential income components. We also disaggregate changes in per capita income into its three components: in-migrant/stayer, out-migrant/ stayer, and in-migrant/out-migrants components.

In terms of census geography, the IRS income-migration data is only given as state-to-state and county-to-county movements, the latter of which we are using here. We match the county-to-county data with the EFIMR by aggregating the data from the counties that constitute each of the 361 metropolitan areas found in the EFIMR data. By matching the data from the counties with their metropolitan areas, we can show movements of households and their average pre-and post-move incomes by metropolitan area.

\section{Economic Freedom, Metropolitan Migration and Income Change}

Our 361 metropolitan areas are parsed into three groups based on their economic freedom scores. We use standardized z-scores to assign each metro area to one of three categories: High ( $+1 \mathrm{sd})$, Medium ( 0.99 to $-0.99 \mathrm{sd})$ and Low ( -1 sd) (Figure 1). Next, we calculate the total amount of migration and income change as recorded in the 2011 to 2015 IRS data files across the economic freedom categories. Metropolitan areas with high levels of economic freedom experienced a net population gain through net in-migration of almost one million people. On the other hand, the other two categories of metropolitan areas lost close to a million people through net out-migration (Figure 2). We also disaggregated net migration of metropolitan areas into intra- and inter-state migration flows. The pattern is similar for both intra- and inter-state migration. We should note at this point that these figures do not sum to zero because the data is not symmetrical. That is, there are migrations in and out of smaller metropolitan, micropolitan and non-metropolitan areas that are not included here. 


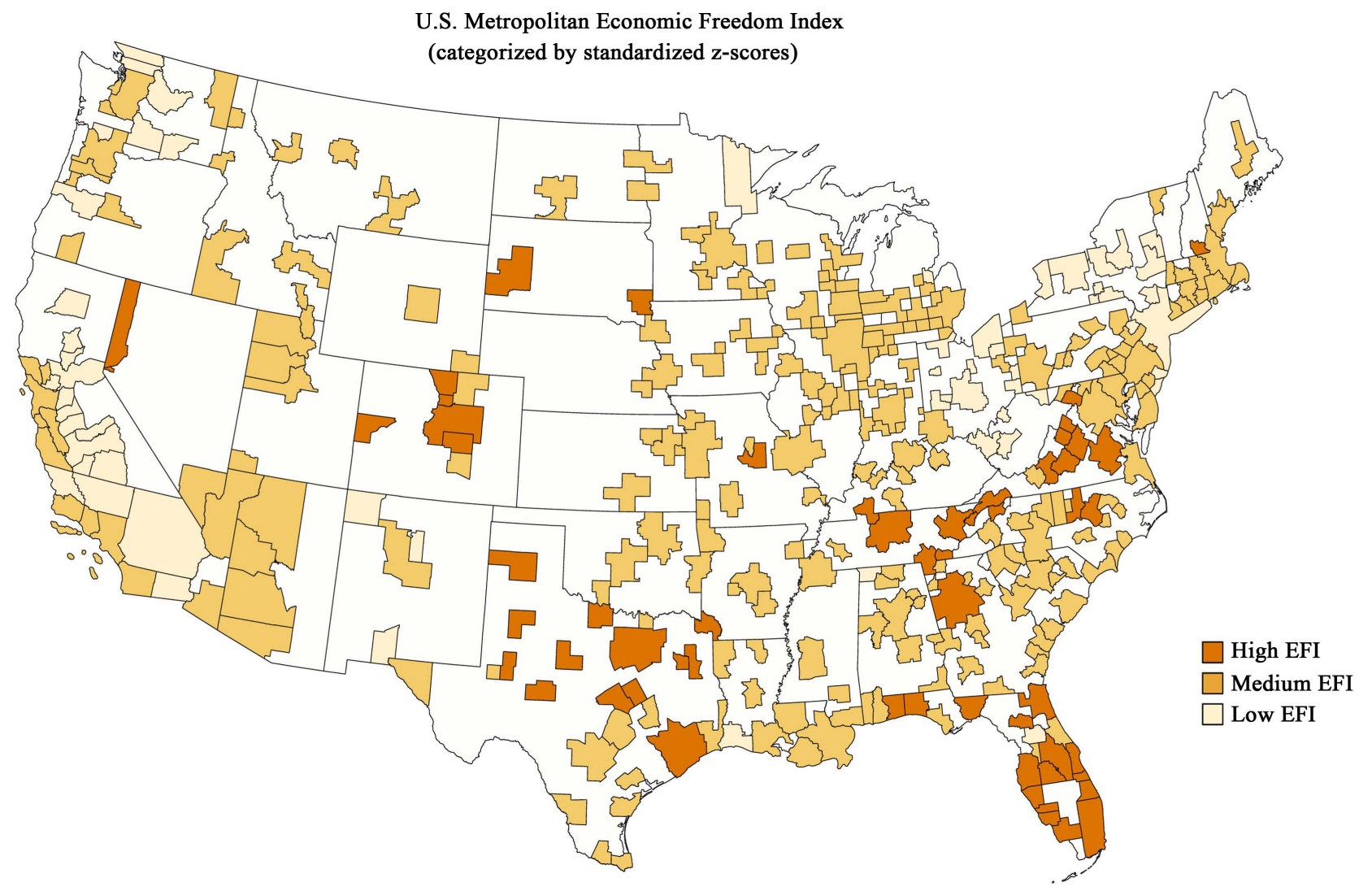

Figure 1. Metro area economic freedom ranking.

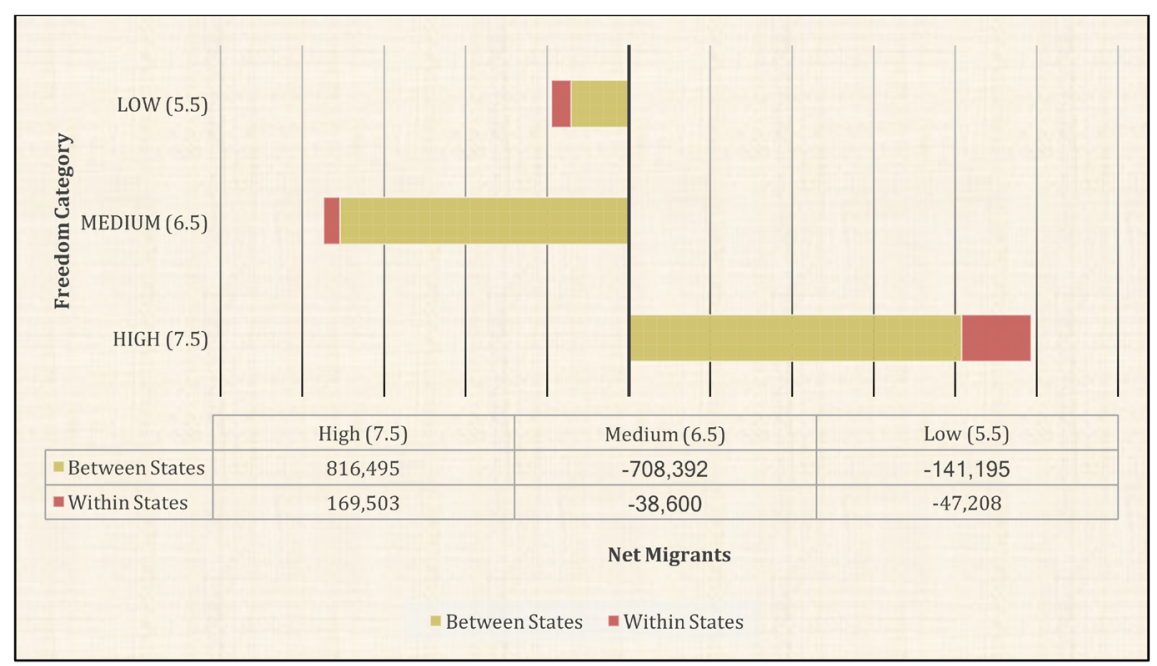

Figure 2. Total net migration in U.S. metro areas by economic freedom index.

\subsection{Aggregate Income Change}

Changes in aggregate income from migration for all metro areas follow a pattern similar to net migration patterns. Metropolitan areas with high levels of economic freedom had higher aggregate income from net-migration, while the medium and low groups had lower levels of aggregate income due to migration. 
Because migration is selective we want to see if it is the net total number of migrants causing income change or differences in income between in- and out-migrants that is the main agent of change. In order to do this, disaggregated income change into two components: a net-migration component (NMC) where areas gain income due to more in- than out-migration, and a differential income component (DIC) where in- and out-migrants have different levels of income. The patterns of metropolitan area income change due to the size and composition of migration flows are shown in Figure 3. Across the three categories of metropolitan area economic freedom, metro areas with high levels of economic freedom had increases in aggregate income from both net migration and differential income components, although net migration is clearly the largest agent of income change. Metropolitan areas with medium and low levels of economic freedom lost income due to both net and differential migration. This suggests that people across the income spectrum are, on average, leaving areas with lower levels of economic freedom and moving towards areas with higher levels of economic freedom.

\subsection{Per Capita Income}

Differences in per capita incomes are not simply the differences between metro areas in average income per person between one year and the next. For example, year one per capita income estimates are derived from metro area residents as of April 1 of the current year. Figure 4 includes all non-migrants from the previous year and each metro areas out-migrants. Year two per capita income estimates include both non-migrants and in-migrants. Thus, year one estimates are "pre-migration" estimates and year two estimates are "post-migration." Again, following Plane (1999) if we denote the number of non-migrants (stayers) as $S$ and their income as $y_{S}$, then

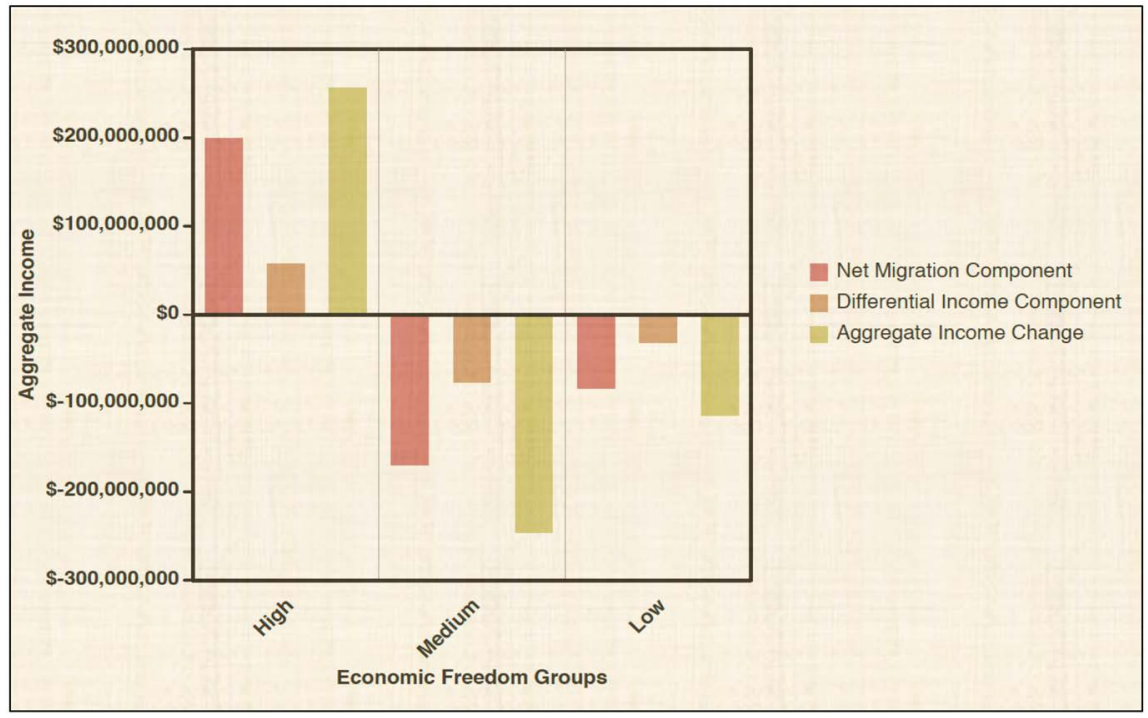

Figure 3. Aggregate income change by income-migration component. 


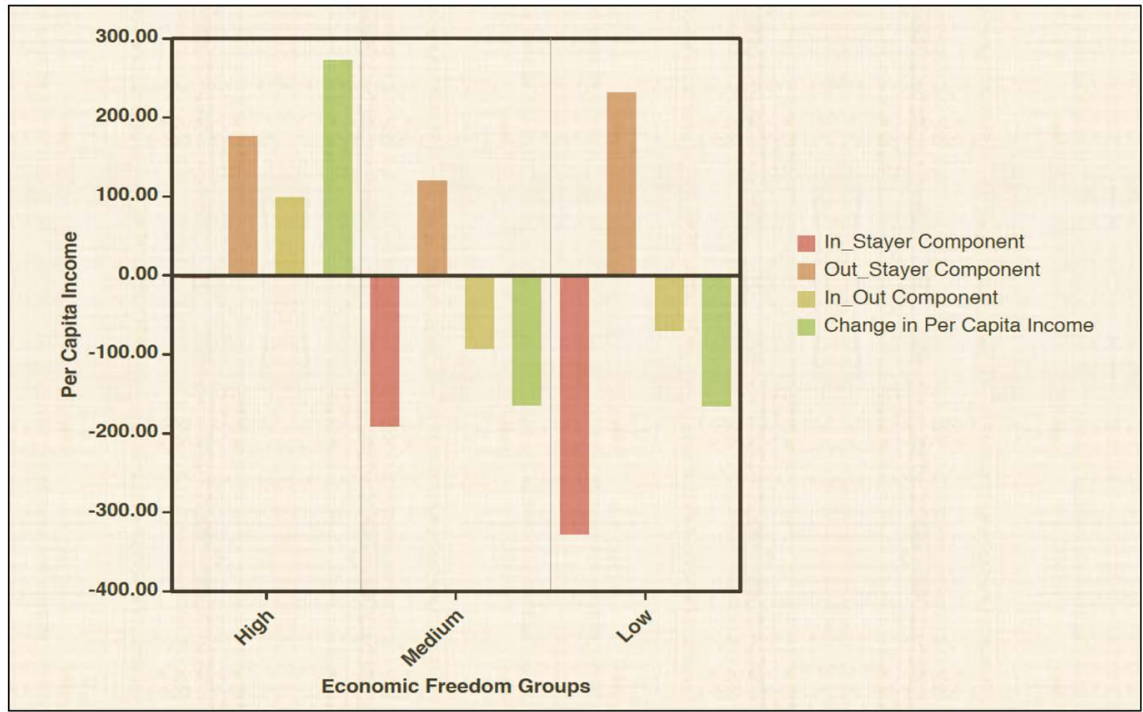

Figure 4. Changes in per capita incomes by income-migration component.

$$
\Delta y=\left[\left(y_{S} s+y_{I} I\right) /(S+I)\right]-\left[\left(y_{S} s+y_{O} o\right) /(S+O)\right]
$$

$S+O$ is the population base at the beginning of the period and $S+I$ is the post-migration population. We can now disaggregate metro area per capita income change into income differentials between in-migrants and stayers, between out-migrants and stayers and between in-migrants and out-migrants. Each component is weighted differently according to its relative size of non-, in-, and out-migrants,

$$
\Delta y=\left[\left(y_{I}-y_{s}\right) I S-\left(y_{O}+y_{S}\right) O S+\left(y_{I}-y_{O}\right) I O\right] /(S+I)(S+O)
$$

We have labeled these components as in-migrant/stayer, out-migrant/stayer, and in-migrant/out-migrant components, and calculate their values by,

$$
\Delta y=\Delta y^{I S C}+\Delta y^{O S C}+\Delta y^{I O C}
$$

where:

$$
\begin{aligned}
\Delta y^{I S C} & =\left(y_{I}-y_{S}\right) I S /[(S+I)(S+O)] \\
\Delta y^{O S C} & =\left(y_{S}-y_{O}\right) O S /[(S+I)(S+O)] \\
\Delta y^{I O C} & =\left(y_{I}-y_{O}\right) I O /[(S+I)(S+O)]
\end{aligned}
$$

Metro areas in the high category experienced, on average, an increase in per capita income over the four years presented here while areas in the medium and low categories had declines in per capita income, on average, due to migration. A number of items stand out. First, it is unusual for in-migrants to have, on average, higher incomes than non-migrants due to the age-structure of migration (young people are more likely to migrate than older people and they tend to have lower incomes). In fact, this is what we see in the low and medium categories where the in-migrant/stayer component is negative, i.e. per capita income 
decreases because in-migrants have lower incomes than stayers. On the other hand, metropolitan areas with a high economic freedom experienced an increase in per capita income because in-migrants had, on average, higher incomes than stayers, which is not what we expected. In fact, metro areas with high levels of economic freedom saw increases in average per capita income from all three components (in-migrants had higher incomes than stayers, out-migrants had lower incomes than stayers, and in-migrants had higher incomes than out-migrants). As would be expected, metro areas in both the medium and low categories had increases in per capita incomes due to the outmigrant/stayer component (out-migrants had, on average, lower incomes than stayers), but these increases were not enough to offset the decreases from in-migrants having lower incomes than both stayers and out-migrants.

\subsection{Within and between State Income Migration}

One further decomposition that we thought would be interesting is examining patterns within and between states. That is, are in-state migrants and out-ofstate migrants similar in terms of where they move relative to levels of economic freedom? The short answer is-it depends. The longer answer is that there are some new patterns, but the overall results are generally the same. First, however it is important to point out that most of the net gains or losses for both migrants and income are primarily from out-of-state migrants. The net gains or losses are smaller within states because there is more bi-lateral migration (thus a smaller net change) whereas longer distance migration tends to be more efficient or effective in redistributing people and income.

For changes in aggregate income, the patterns pretty much mirror the overall change-except for the differential income component for within state movers. Here the pattern is reversed with metropolitan areas with high levels of economic freedom losing income because, on average, in-migrants had lower incomes than out-migrants, while for metropolitan areas in the low category the differential income component was actually positive. However, the net aggregate income gained was not enough to offset losses in the net migration component and thus the overall aggregate income change is the same (although of a significantly lower magnitude).

Changes in per capita income, however, are more varied. For example, in the in-state migration Table 1(a), we can see that in all three groups per capita income declines due to in-migrants having lower incomes than stayers, and increases because out-migrants have lower incomes than stayers, which is what we would expect to see if migrants have lower incomes (because they are younger) than those who do not migrate. These two processes more-or-less offset each other so the deciding factor as whether or not per capita income increased or decreased from within state migration is primarily due to differences in income between in-migrants and out-migrants. As we saw earlier the end result is the same. The between state migration changes in per capita income are just the 
Table 1. (a) Within state aggregate and per capita income change; (b) Between state aggregate and per capita income change.

(a)

\begin{tabular}{cccccccc}
\hline & $\begin{array}{c}\text { Net } \\
\text { migration } \\
\text { (billions) }\end{array}$ & $\begin{array}{c}\text { Differential } \\
\text { Income } \\
\text { (billions) }\end{array}$ & $\begin{array}{c}\text { Income } \\
\text { Change } \\
\text { (billions) }\end{array}$ & ISC & OSC & IOC & $\begin{array}{c}\text { PCInc } \\
\text { Change }\end{array}$ \\
\hline High & 3.6 & -1.2 & 2.5 & -321 & 350 & 26 & 56 \\
Medium & -1.7 & -0.45 & -2.1 & -262 & 248 & -14 & -27 \\
Low & -1.7 & 1.2 & -0.5 & -335 & 327 & -5 & -13 \\
\hline
\end{tabular}

(b)

\begin{tabular}{cccccccc}
\hline & $\begin{array}{c}\text { Net } \\
\text { migration } \\
\text { (billions) }\end{array}$ & $\begin{array}{c}\text { Differential } \\
\text { Income } \\
\text { (billions) }\end{array}$ & $\begin{array}{c}\text { Income } \\
\text { Change } \\
\text { (billions) }\end{array}$ & ISC & OSC & IOC & $\begin{array}{c}\text { PCInc } \\
\text { Change }\end{array}$ \\
\hline High & 26.7 & 6.2 & 32.9 & 533 & -272 & -13 & 248 \\
Medium & -27.5 & -9.3 & -36.7 & 103 & -229 & -99 & -225 \\
Low & -3.6 & -3.1 & -6.7 & -47 & -111 & -43 & -200 \\
\hline
\end{tabular}

opposite of the within state movements (Table 1(b)). Here metropolitan areas in all groups gained income because in-migrants had higher incomes, on average, than non-migrants but only metro areas with low levels of economic freedom had declines in per capita incomes due to in-migrants having lower incomes than stayers. In the end, similar to the overall pattern, only metropolitan areas with high levels of economic freedom experienced, on average, net increases in per capita incomes as a result of migration.

One observation that stands out is what appears to be a large selectivity difference of within-state and between state-migrants. Within-state migrants tend, all else being equal, to have lower incomes than between-state migrants. The broad pattern shown here does suggest that people are aware of differences in the mix of government size, taxation, and regulatory regimes among metropoli$\tan$ areas. This awareness may come indirectly through employment growth and cost-of-living differences, or it may come directly through knowledge of specific policies, regulations, and taxes. However such knowledge is gained, it does appear that people do "vote with their feet" to indicate preferences. The most important votes, however, are made by out of state migrants. A second observation is that metro areas with high levels of economic freedom actually lost income through differential migration within the state, although overall aggregate income increased. This suggests, at least in terms of intra-state migration, that migrants who either have or can command higher incomes are less sensitive to tax and regulatory burdens than those with lower incomes.

\section{Example Metropolitan Areas}

Using the EFIMR we identified at least one metropolitan area from each freedom category, with two from the high group and two from the low group. The 
metro areas included here were chosen because they reveal the complexity of how total-migration and the composition-of-migrating populations interacting with sending and receiving areas can affect spatial patterns of income change. Table 2 contains the results showing aggregate income change due to the net migration and differential income components of total, within-state, and between-state income-migration for selected metro areas and Table 3 shows changes in per capita income by component.

One thing that these example cities illustrate is that there is not a direct correlation between levels of economic freedom, net migration and positive changes in local aggregate income (including the Miami (high EFI category), Austin (medium high EFI category) and Sacramento (low EFI category) metro areas. For example, Miami lost income because more people moved to other areas in the state and to out-of-state locations than moved there (see the net-migration column in Table 3). So how then did Miami actually gain income through migration? The column on Differential Income in Table 2 provides the answer: massive amounts of income gain due to the higher incomes of in-migrants when compared to out-migrants and stayers. Miami is a good example of a metropolitan area that attracts higher income earning individuals from out-of-state and sends lower income earning people mostly to other regions of the state. Austin,

Table 2. Aggregate income change by metropolitan area and component of change.

\begin{tabular}{|c|c|c|c|c|c|c|c|c|c|c|}
\hline \multirow{2}{*}{ Metro Area } & \multirow{2}{*}{ EFI } & \multicolumn{3}{|c|}{$\begin{array}{l}\text { Net migration component } \\
\text { (millions) }\end{array}$} & \multicolumn{3}{|c|}{$\begin{array}{l}\text { Differential Income } \\
\text { Component (millions) }\end{array}$} & \multicolumn{3}{|c|}{$\begin{array}{l}\text { Income Change } \\
\text { (millions) }\end{array}$} \\
\hline & & $\begin{array}{l}\text { Same } \\
\text { State }\end{array}$ & $\begin{array}{l}\text { Different } \\
\text { State }\end{array}$ & Total & $\begin{array}{l}\text { Same } \\
\text { State }\end{array}$ & $\begin{array}{l}\text { Different } \\
\text { State }\end{array}$ & Total & $\begin{array}{l}\text { Same } \\
\text { State }\end{array}$ & $\begin{array}{l}\text { Different } \\
\text { State }\end{array}$ & Total \\
\hline Nashville-Davidson-Murfreesboro-Franklin & 8.0 & 130 & 960 & 972 & 40 & 92 & 249 & 170 & 1052 & 1221 \\
\hline Miami-Fort Lauderdale-West Palm Beach & 7.5 & -1118 & -861 & -2128 & 157 & 7604 & 7910 & -961 & 6743 & 5783 \\
\hline Austin-Round Rock & 7.3 & 728 & 6147 & 6629 & 361 & -911 & -303 & 1089 & 5237 & 6325 \\
\hline Chicago-Naperville-Elgin & 6.4 & -319 & -4910 & -4763 & 264 & -2692 & -2893 & -55 & -7602 & -7656 \\
\hline Sacramento-Roseville-Arden-Arcade & 5.6 & 603 & -151 & 463 & 132 & -167 & -45 & 736 & -318 & 418 \\
\hline Los Angeles-Long Beach-Anaheim & 5.2 & -3010 & -2058 & -5125 & 610 & -501 & 166 & -2400 & -2559 & -4959 \\
\hline
\end{tabular}

Table 3. Per capita income change by metropolitan area and component of change.

\begin{tabular}{|c|c|c|c|c|c|c|c|c|c|c|}
\hline \multirow{2}{*}{$\begin{array}{c}\text { Metro Area } \\
\text { EFI }\end{array}$} & & \multicolumn{4}{|c|}{ Same State } & \multicolumn{4}{|c|}{ Different State } & \multirow{2}{*}{$\begin{array}{l}\text { Total } \\
\text { pc inc } \\
\text { change }\end{array}$} \\
\hline & & ISC & OST & IOC & PC Inc & ISC & OST & IOC & PC Inc & \\
\hline Nashville-Davidson-Murfreesboro-Franklin & 8.0 & 850 & -778 & 73 & 144 & 3102 & -2325 & 174 & 951 & 1095 \\
\hline Miami-Fort Lauderdale-West Palm Beach & 7.5 & 714 & -693 & 113 & 133 & 7705 & -2684 & 5550 & 10571 & 10704 \\
\hline Austin-Round Rock & 7.3 & -226 & 460 & 902 & 1136 & -644 & 537 & -2341 & -2447 & -1311 \\
\hline Chicago-Naperville-Elgin & 6.4 & -449 & 489 & 354 & 394 & -1968 & 928 & -4022 & -5062 & -4668 \\
\hline Sacramento-Roseville-Arden-Arcade & 5.6 & -1355 & 1359 & 77 & 81 & -810 & 555 & -59 & -314 & -233 \\
\hline Los Angeles-Long Beach-Anaheim & 5.2 & -670 & 894 & 12 & 236 & -29 & -57 & -7 & -93 & 143 \\
\hline
\end{tabular}


Texas is just the opposite of Miami. According to the IRS migration data, Austin received the greatest number of net migrants between 2011/12 and 2014/2015. This pattern is reflected in Austin's increase in aggregate income due to net migration. However, Austin, unlike Miami, experienced a decrease in total aggregate income due to the compositional flow of migrants with in-migrants having lower incomes than stayers or out-migrants. Nevertheless, total income change was positive for both Miami and Austin even though the increases were gained through different types of migration patterns.

Los Angeles is similar to Miami except its increase in income from the differential income component is not large enough to offset the large decrease in aggregate income from the net-migration component. Aggregate income in Los Angeles declined due to net out-migration both to in-state and out-of-state locations, but actually gained aggregate income through the differential income component from in-state migration. This suggests that for in-state migration, lower income people leave Los Angeles for other areas of the state, and higher income individuals move to Los Angeles. For out-of-state migration, Los Angeles loses aggregate income from both income migration components.

Sacramento presents an interesting case of a large metropolitan area with a relatively low economic freedom score that still gained population from netmigration and experienced an increase in aggregate income, which is not what we expected. However, once we disaggregate between in-state and out-of-state migration it is easier to explain. All of Sacramento's gains in aggregate income come from within state migrants. Sacramento actually loses aggregate income from migration to other states. The gains from the in-state migration more than offset the losses due to out-of-state migration. Sacramento is relatively more attractive to in-state rather than out-of-state migrants and is a good indicator of why it is important to disaggregate by intra- and inter-state migration. Nashville and Chicago represent examples of metro areas with a large number of net in-migration (Nashville) and net out-migration (Chicago) and the concomitant changes in aggregate income expected from their level of economic freedom. Whether or not it is in-state or out-of-state migration, Nashville increases in population and income while Chicago declines.

We also examined per capita income changes disaggregated by in-, out-, and non-migrants both within-and between-states. These results can be seen in Table 3. Just as a quick reminder, changes in metropolitan wide per capita income due to migration is determined by differences between inmigrant/stayer income, out-migrant/stayer income, and in-migrant/out-migrant income. The data is also grouped by within- and between-state migration. Examining per capita income is important because it can be positive even if aggregate income change is negative, and negative even if aggregate income change is positive. This is exactly what we see happening with Austin, Sacramento, and Los Angeles. Austin and Sacramento both experienced increases in total aggregate income but had rather large declines in per capita income due to the compositional mix of 
in- and out-migrants. In Austin's case, the largest contributor to the decline in per capita income was in-migrants having significantly lower average incomes than out-migrants, together with lower incomes than stayers.

Although Austin is a large metropolitan area, it is also the state capitol and houses the University of Texas' main campus, which may explain the large inflow of people with lower incomes. Sacramento is a bit different in that almost all of the decline in per capita income is due to the in-migrant-stayer component. Los Angeles experienced just the opposite impact when aggregate income declined, but per capita income increased. The increase came from the relatively lower incomes of out-migrants compared to stayers and in-migrants, but only for in-state migration. Both Sacramento and Los Angeles had larger impacts from in-state as opposed to out-of-state migration. All of the other metro areas studied had larger impacts from migration between states rather than within state, although all of metros increased in per capita income from within state migrants and four of the six had losses in per capita incomes from out-of-state migrants. The two exceptions were the two cities with the highest EFIs: Nashville and Miami. These two metro regions were also distinctive in that per capita income increased because in-migrants had higher average incomes than both stayers and out-migrants, but both had declines in per capita income because out-migrants also had higher income than stayers. This certainly begs the question of why would both in- and out-migrants have higher incomes than stayers? It may have to do with the size and structure of the metropolitan areas and their neighbors, but without finer grained geographical data, it is impossible to determine.

\section{Conclusions}

Patterns of migration are influenced by not only individual/family characteristics and circumstances, but also by the characteristics of sending and receiving locations. The purpose of this paper is to examine the effect of differing levels of economic freedom among U.S. metropolitan areas on migration and income change. While economic freedom is only one of many factors that affect migratory patterns, previous research, as discussed earlier in the paper, has shown that, all else being equal, economic freedom has both direct and indirect effects on where people move from and where they move to.

This research supports previous findings by showing that individuals/families tend to move away from metropolitan areas with lower levels of economic freedom and move to metropolitan areas with higher levels of economic freedom, all else being equal. However, this relationship is not completely linear and it is confounded by whether or not the move is within or between states. We also find that both aggregate and per capita income change due to migration are generally positive for metropolitan areas with greater levels of economic freedom and negative for metropolitan areas with lower levels of economic freedom. For most metropolitan areas the increases or losses in aggregate and per capita 
income are due to differences in net migration (i.e. Nashville). Differences in income between in- and out-migrants (differential income) also play an important role for some metropolitan areas, for example Los Angeles experienced net out-migration and a decline in aggregate income, but actually gained in per capita income due to in-migrants with higher average income than out-migrants, all of which was due to in-state not out-of-state migrants. Overall economic freedom seems to be an important determinant of migration and have positive effects on aggregate and per capita income.

There are a few caveats. First, this research only covers four years and may not represent longer-term trends. How the IRS gathers this data set changed significantly in 2011/2012 and thus created a discontinuity with previous year's data. The good news is that current data collection methods are more comprehensive and inclusive and thus provide a better, although still somewhat murky, picture of migration and income change in the U.S. Second, we simply exam net-migration disaggregated by intra- and interstate moves between metropolitan areas controlling only for differences in economic freedom. There certainly are other factors that influence spatial migration patterns, and many of these factors are more important than economic freedom (see literature discussed earlier). A more rigorous modeling approach is needed in order to control for other important variables and determine their relative contribution to variations in spatial mobility, as well as controlling for specific geographic context (see Shumway \& Davis, 2016). Nevertheless, this research does suggest that economic freedom is important and should be considered one of the core variables included within any extensive examination of spatial mobility. It is also important relative to policy as a number of the components that determine levels of economic freedom can be influenced by local and state governments, particularly those relating to entry barriers to certain types of economic activities, local tax levels, transfer payments, and size of local government payrolls. Judicious use of regulatory and fiscal instruments in order to enhance local economies is within the purview of metropolitan and state governments. Finally, and most importantly, this research supports the idea that, in a federal system that allows some level of autonomy among its sub-units, people can and do use migration as a means of expressing their preferences for different types of governments, government programs, and government interventions in the market.

\section{References}

Acemoglu, D., Johnson, S., \& Robinson, J. (2005). The Rise of Europe: Atlantic Trade, Institutional Change, and Economic Growth. American Economic Review, 95, 546-579. https://doi.org/10.1257/0002828054201305

Ali, A. M. (1997). Economic Freedom, Democracy and Growth. Journal of Private Enterprise, 13, 1-20.

Ali, A. M., \& Crain, W. M. (2002). Institutional Distortions, Economic Freedom, and Growth. Cato Journal, 21, 415-426. 
Ashby, N. J. (2007). Economic Freedom and Migration Flows between US States. Southern Economic Journal, 73, 677-697.

Ashby, N. J., \& Sobel, R. S. (2008). Income Inequality and Economic Freedom in U.S. States. Public Choice, 134, 329-346. https://doi.org/10.1007/s11127-007-9230-5

Ayal, E. B., \& Karras, G. (1998). Components of Economic Freedom and Growth: An Empirical Study. The Journal of Developing Areas, 32, 327-338.

Bergh, A., \& Karlsson, M. (2010). Government Size and Growth: Accounting for Economic Freedom and Globalization. Public Choice, 142, 195-213. https://doi.org/10.1007/s11127-009-9484-1

Carlsson, F., \& Lundström, S. (2002). Economic Freedom and Growth: Decomposing the Effects. Public Choice, 112, 335-344. https://doi.org/10.1023/A:1019968525415

Cebula, R. J. (2014). The Impact of Economic Freedom and Personal Freedom on Net In-Migration in the U.S.: A State-Level Empirical Analysis, 2000 to 2010. Journal of Labor Research, 35, 88-103. https://doi.org/10.1007/s12122-014-9175-7

Cebula, R. J., \& Clark, J. R. (2012). Lessons from the Experience of OECD Nations on Macroeconomic Growth and Economic Freedom, 2004-2008. International Review of Economics, 59, 231-243. https://doi.org/10.1007/s12232-012-0162-0

Clark, D. E., \& Hunter, W. J. (1992). The Impact of Economic Opportunity, Amenities and Fiscal Factors on Age-Specific Migration Rates. Journal of Regional Science, 32, 349-365. https://doi.org/10.1111/j.1467-9787.1992.tb00191.x

Compton, R. A., Giedeman, D. C., \& Hoover, G. A. (2011). Panel Evidence on Economic Freedom and Growth in the United States. European Journal of Political Economy, 27, 423-435. https://doi.org/10.1016/j.ejpoleco.2011.01.001

Dawson, J. W. (2003). Causality in the Freedom-Growth Relationship. European Journal of Political Economy, 19, 479-495. https://doi.org/10.1016/S0176-2680(03)00009-0

Dopp, T. (2016). Tepper's Move May Affect New Jersey Budget, Forecaster Warns. http://www.bloomberg.com/markets

Edwards, C., \& Mitchell, D. J. (2008). Global Tax Revolution: The Rise of Tax Competition and the Battle to Defend It. Washington DC: Cato Institute, 250.

Faggian, A., Olfert, M. R., \& Partridge, M. D. (2012). Inferring Regional Well-Being from Individual Revealed Preferences: The "Voting with Your Feet" Approach. Cambridge Journal of Regions, Economy and Society, 5, 163-180. https://doi.org/10.1093/cjres/rsr016

Faria, H. J., \& Montesinos, H. M. (2009). Does Economic Freedom Cause Prosperity? An IV Approach. Public Choice, 141, 103-127. https://doi.org/10.1007/s11127-009-9440-0

Farr, W. K., Lord, R. A., \& Wolfenbarger, J. L. (1998). Economic Freedom, Political Freedom, and Economic Well-Being: A Causality Analysis. Cato Journal, 18, 247-262.

Ferguson, M., Ali, K., Olfert, M., \& Partridge, M. (2007). Voting with Their Feet: Jobs versus Amenities. Growth and Change, 38, 77-110. https://doi.org/10.1111/j.1468-2257.2007.00354.x

Friedman, M. (1962). Capitalism and Freedom. Chicago, IL: University of Chicago Press. Galor, O. (2011). Unified Growth Theory. Princeton, NJ: Princeton University Press.

Goldsmith, A. A. (1995). Democracy, Property Rights and Economic Growth. The Journal of Development Studies, 32, 157-174. https://doi.org/10.1080/00220389508422409

Gwartney, J. D., \& Lawson, R. A. (2006). The Impact of Tax Policy on Economic Growth, Income Distribution, and Allocation of Taxes. Social Philosophy and Policy, 23, 28-52. 
Heckelman, J. C. (2000). Economic Freedom and Economic Growth: A Short-Run Causal Investigation. Journal of Applied Economics, 3, 71-91.

Heckelman, J. C., \& Stroup, M. D. (2000). Which Economic Freedoms Contribute to Growth? Kyklos, 53, 527-544. https://doi.org/10.1111/1467-6435.00132

Heller, L. R., \& Stephenson, E. F. (2014). Economic Freedom and Labor Market Conditions: Evidence from the States. Contemporary Economic Policy, 32, 56-66.

https://doi.org/10.1111/coep.12031

Holcombe, R. G. and Lacombe, D. J. (2004). The Effect of State Income Taxation on Per Capita Income Growth. Public Finance Review, 32, 292-312. https://doi.org/10.1177/1091142104264303

King, E. M., Montenegro, C. E., \& Orazem, P. F. (2012). Economic Freedom, Human Rights, and the Returns to Human Capital: An Evaluation of the Schultz Hypothesis. Economic Development and Cultural Change, 61, 39-72. https://doi.org/10.1086/666948

Kuckertz, A., Berger, E. S. C., \& Mpeqa, A. (2016). The More the Merrier? Economic Freedom and Entrepreneurial Activity. Journal of Business Research, 69, 1288-1293. https://doi.org/10.1016/j.jbusres.2015.10.094

Lucas, R. E. (2002). Lectures on Economic Growth. Cambridge, Mass.: Harvard University Press.

Mulholland, S. E. and Hernandez-Julian, R. (2013). Does Economic Freedom Lead to Selective Migration by Education? Journal of Regional Analysis and Policy, 43, 65-87.

Oates, W. E. (2003). An Easy on Fiscal Federalism. Economic Perspectives, 37, 1120-1150.

Partridge, M. D. (2010). The Dueling Models: NEG vs Amenity Migration in Explaining US Engines of Growth. Papers in Regional Science, 89, 513-536. https://doi.org/10.1111/j.1435-5957.2010.00315.x

Plane, D. A. (1999). Geographical Pattern Analysis of Income Migration in the United States. International Journal of Population Geography, 5, 195-212. https://doi.org/10.1002/(SICI)1099-1220(199905/06)5:3<195::AID-IJPG138>3.0.CO;2-K

Romer, P. M. (1986). Increasing Returns and Long-Run Growth. Journal of Political Economy, 94, 1002. https://doi.org/10.1086/261420

Romer, P. M. (1990). Endogenous Technological Change. Journal of Political Economy, 98, S71. https://doi.org/10.1086/261725

Rosen, S. (1983). Specialization and Human Capital on JSTOR. Journal of Labor Economics, 1, 43-49. https://doi.org/10.1086/298003

Shumway, J. M., \& Davis, J. A. (2016). Economic Freedom, Migration, and Income Change in the United States: 1995 to 2010. The Professional Geographer, 68, 390-398. https://doi.org/10.1086/298003

Stansel, D. (2013). An Economic Freedom Index for US Metropolitan Areas. Journal of Regional Analysis and Policy, 43, 3-20.

Tiebout, C. M. (1956). A Pure Theory of Local Expenditures. The Journal of Political Economy, 64, 416-424. https://doi.org/10.1086/257839

Tullock, G. (1971). Public Decisions as Public Goods. Journal of Political Economy, 79, 913-918. https://doi.org/10.1086/259799

US Internal Revenue Service (2015). IRS County-to-County Migration and Income Data. Washington DC: IRS Statistics of Income Division. 
Weingast, B. R. (1995). Economic Role of Political Institutions: Market-Preserving Federalism and Economic Development. Journal of Law, Economics, and Organization, 11, $1-31$.

Xu, Z. H. and Li, H. Z. (2008). Political Freedom, Economic Freedom, and Income Convergence: do Stages of Economic Development Matter? Public Choice, 135, 183-205. https://doi.org/10.1007/s11127-007-9253-y 